\title{
O ESTATUTO EPISTEMOLÓGICO DA PSICANÁLISE FREUDIANA: ENERGÉTICA E HERMENÊUTICA
}

\author{
Izabel Cristina Barbelli \\ PPGFIL - UFSCar
}

\begin{abstract}
The purpose of this work is to discuss the epistemological statute of the Freudian psychoanalysis, through the concepts of the energetic and the hermeneutic. To reach our goal, we started with the hypothesis that interpretation is one of the fundamental elements characterizing the epistemological statute of psychoanalysis. In fact, although considering psychoanalysis as a natural science, Freud doesn't restrict the treatment of both psychic and endopsychic phenomena to a mere objective analysis as the empirical sciences have done, treating their objects as a researcher's external reality. In this sense, Freud feels that it is necessary to create new experimental and theoretical conditions to manage the intentional and causal dimensions in which the human mental dynamics are processed. In this point the interpretation has been brought as an instrument to comprehend the human mental dynamics.
\end{abstract}

iKeywords: Psychoanalysis; epistemology; interpretation; energetic; hermeneutic.

Resumo: 0 propósito deste trabalho é discutir o estatuto epistemológico da psicanálise freudiana, através dos conceitos de energética e de hermenêutica. Para alcançarmos nosso objetivo partiremos da hipótese de que a interpretação é um dos elementos fundamentais que caracterizam o estatuto desta psicanálise. De fato, Freud, apesar de ter considerado a psicanálise como uma ciência natural, não restringe seu tratamento dos fenômenos psíquicos e endopsíquicos a uma mera análise objetiva tal como feita pelas ciências empíricas, as quais pretendem tratar seus objetos como uma realidade externa ao pesquisador; nesse sentido, ele sente a necessidade de criar novas condições experimentais e teóricas para conseguir lidar com as dimensões intencional e causal em que se processa a dinâmica mental humana. É aqui que entra a interpretação enquanto instrumento de compreensão desta última.

Palavras-chave: Psicanálise; epistemologia; interpretação; energética; hermenêutica. 
O advento da psicanálise freudiana sugeriu uma revisão dos paradigmas epistemológicos das ciências de seu tempo no que se refere ao estudo do ser humano, não no sentido de que as ciências já existentes foram impelidas a se reestruturarem epistemologicamente a fim de serem bem empregadas no estudo da mente humana, mas no de que as dificuldades epistêmicas com que se deparou a psicanálise tornaram necessária a busca de uma peculiar epistemologia para lidar de forma mais eficaz com a mente humana, já que as ciências já constituídas não satisfaziam plenamente as condições de pesquisa desta última.

As controvérsias entre Freud e Breuer deixam explícito que aquele compreendia que a estrutura ontológica da mente humana não podia ser tratada e concebida como um puro sistema físico-químico objetivamente experimentável, cujas leis de comportamento podiam ser representadas fielmente apenas por uma racionalidade lógico-matemática. Era necessário buscar um novo tipo de racionalidade epistêmica que empregasse métodos melhor adaptados à busca das causas e dos motivos da patologia mental não em processos fisiológicos, mas em processos psicológicos, especialmente aqueles de natureza inconsciente.

Esta busca por um novo tipo de racionalidade epistêmica, caracterizou-se por complementar, de maneira reestruturadora, a epistemologia das ciências empíricas com um sistema epistemológico hermenêutico, cuja análise elucidativa recairá não em uma dimensão causal constituída por mecanismos energéticos e pulsionais, mas em uma dimensão intencional constituída por estruturas ambíguas de significação, cujo processo fenomênico sobrepõe-se sobre aqueles mecanismos energéticos.

Contudo, a revisão epistêmica sugerida pela psicanálise freudiana, ao invés de se desenvolver tranqüilamente no sentido da implantação irrefutável de um sistema epistemológico sólido quanto ao seu estatuto semântico (ressalta-se aqui que Freud acreditava que a psicanálise era ciência natural), trouxe diversas controvérsias no plano das análises epistemológicas posteriores sobre a cientificidade da psicanálise. Contemporaneamente, a situação destas análises não apresenta um consenso geral, mas um rico ambiente de tensão matizado por diferentes perspectivas, como veremos ao longo do desenvolvimento deste trabalho.

Nesse sentido, procuraremos contribuir com essa discussão através do elemento interpretativo da epistemologia freudiana, tendo em vista que, para 
se entender o tipo de cientificidade da psicanálise, é necessário caracterizar seus instrumentos teórico-metodológicos a fim de compará-los à epistemologia das ciências empíricas, caracterização esta que passa pela análise do papel da interpretação na psicanálise. Contudo, não iremos procurar aqui uma definição a respeito dessa cientificidade, mas apenas explicitar alguns aspectos epistêmicos da interpretação psicanalítica.

\section{A especificidade da psicanálise enquanto ciência}

No âmago do termo 'psicanálise' reside um pressuposto epistêmico que pretende lhe imprimir uma tendência de aproximação racional e metódica do objeto a que diz respeito; qual seja: o de que se busca uma compreensão verdadeira acerca do psiquismo humano, o que equivale a dizer que, na esteira da tradição do Ocidente no que se refere à busca da verdade, deve-se estruturar uma ciência do referido psiquismo, segundo uma sistematização analítica tal qual aquela que se encontra nas pesquisas das ciências bem sucedidas, isto é, das ciências naturais e formais. O próprio Freud, ao nomear o tipo de investigação que havia inaugurado com o termo 'psicanálise, ' tinha em mente uma teoria e uma metodologia que surgiram enquanto ramificação da ciência natural, isto é, o âmbito de ambas estava sob a categoria da ciência natural. Contudo, o desenvolvimento da psicanálise freudiana suscitou análises filosóficas nas quais, da sua estrutura epistemológica foram evidenciados um arcabouço lógico-conceitual e uma metodologia que apresentavam profundas dessemelhanças em relação às ciências tipicamente naturais, fato este que apresenta a problemática essencial da psicanálise, já que levou muitos estudiosos a negarem a existência de uma cientificidade nesta última, ou restringi-la ao campo das ciências humanas.

Atualmente, atesta-se ainda o decurso das referidas análises, já que o caráter problemático da psicanálise cria intrincados obstáculos ao exame conceitual dos estudiosos sobre o assunto.

Em vista disso, pretendemos aqui fazer algumas reflexões iniciais a respeito da natureza epistemológica da psicanálise freudiana a fim de prepararmos o terreno, para nos posteriores tópicos do artigo, nos aprofundarmos um pouco na textura lógica que caracteriza este saber teórico-prático.

De início, é preciso considerar que há um complicador que está estreitamente vinculado ao panorama histórico no qual a psicanálise freudiana constituiu-se, a saber, um período de grandes revoluções no contexto científi- 
co do século XIX suscitadas pela emergência de saberes referentes à esfera do humano e sua história (as ciências humanas), os quais se instauraram conflituosamente em relação às ciências tradicionais da época:

[...] no momento em que a psicanálise freudiana emerge para a cientificidade, deveria ver-se confrontada com a questão imediata de seu lugar num tabuleiro que este longo processo constituiria. A emergência ao saber devia responder a interpelação preliminar. Quando Freud intitula a psicanálise de "ciência da natureza", percebemos que respondia a essa interpelação, na medida em que o "quem sou?" pelo qual um saber anunciava sua identidade estava, de fato, em condições de responder à questão forjada pela história, lá lembrada por nós: "És ciência da natureza ou do espírito"? (ASSOUN, 1983, p.48)

Neste contexto, quando surge a psicanálise, imediatamente evidenciase uma acentuada singularidade devido à composição investigativa sobre a qual ela está estruturada: boa parte da elaboração da psicanálise pretende se assentar, a princípio, nos estudos neurofisiológicos, que inclinam Freud a conceber a mente física e quimicamente, o que o afasta do tradicional dualismo para aproximá-lo de um monismo reducionista que imprime na psicanálise um caráter científico. Um exemplo privilegiado desta tendência está no manuscrito - desconhecido na época, já que fazia parte da correspondência privada entre Freud e Fliess - Projeto de uma psicologia, de $1895^{1}$. Todavia, à psicanálise foram adequados conceitos mentais retirados de uma hermenêutica implícita nas investigações de Freud que tinham como âmbito a prática clínica.

Deste quadro decorre a seguinte questão: trata-se na psicanálise de uma explicação ${ }^{2}$, de uma interpretação ${ }^{3}$ ou de ambas? Consideremos algumas das diferentes perspectivas para se responder a esta pergunta, em particular, as análises de Assoun (1983) e de Ricoeur (1977):

Assoun considera a psicanálise como uma ciência natural:

\footnotetext{
${ }^{1}$ As obras de Sigmund Freud lidas na tradução da Edição Standard Brasileira foram cotejadas com as correspondentes obras da tradução Argentina da Editora Amorrortu (Buenos Aires, 1976).

${ }^{2}$ No sentido de se apontarem as causas de um processo, subentendendo-se a sujeição das mesmas a uma lei geral.

${ }^{3}$ No contexto de uma compreensão do sentido de uma manifestação psíquica.
} 
Não há lugar para dicotomizarmos a démarche psicanalítica em uma parte explicativa (na linha das ciências da natureza) e em outra interpretativa (na linha de qualquer ciência humana). Isto significaria interiorizarmos a distinção. Não somente a psicanálise é ciência da natureza, como não se prolonga, pelo menos se levarmos a sério a tese freudiana, de uma dimensão hermenêutica (ASSOUN, 1983, p.48)

Deste posicionamento conceitual de Assoun (1983), o primeiro ponto a ser destacado confere à psicanálise um caráter epistêmico cuja origem não se encontra na linha investigativa concernente à interpretação típica das ciências humanas (hermenêutica), e nem tal caráter constitui-se da mesma linha interpretativa. Este quadro assim se apresenta, pois, está estritamente vinculado a uma peculiaridade própria à racionalidade epistêmica em que se fundamenta a psicanálise; na história da psicanálise pode-se ver a estruturação de uma ciência munida dos necessários conceitos fundamentais que toda ciência natural deve ter, e na qual emerge um ponto de vista interpretativo fundamentado na análise clínica -, que de forma alguma resulta numa reconfiguração da identidade desta ciência.

Para compreendermos melhor esta concepção de Assoun (1983), vejamos como ele ressitua o termo alemão Deutung. Segundo ele a Deutung [interpretação] freudiana não está dissociada da Erklärung [explicação], e a interpretação deve ser entendida como uma variante da explicação.

Um dos fatos que levaram Assoun (1983) a tirar tal conclusão reside em que o processo psicanalítico, que se compõe, de um lado, de um conteúdo manifesto e, de outro, de um conteúdo latente, não comporta senão um procedimento intelectual, cujo, direcionamento figura uma explicação efetuada segundo um modo interpretativo. Isto é, na psicanálise o processo investigativo estrutura-se num esquema causal ${ }^{4}$ em que se faz necessária uma interpretação a respeito da função significante das associações oníricas, o que implica numa concomitante explicação, busca de compreensão e elucidação do conteúdo latente, o qual por sua vez participa da constituição destas últimas.

${ }^{4}$ Não necessariamente comprometido, aqui com leis. Tratar-se-ia mais, pensamos nós, de uma causalidade singular. 
Diferentemente de Assoun, Paul Ricoeur coloca a psicanálise freudiana do lado das ciências humanas (1977, p.286): “Não, a psicanálise não é uma ciência de observação, porque é uma interpretação, mais comparável à história do que à psicologia”. Segundo este filósofo, justamente por ser o campo investigativo da psicanálise o aparelho psíquico, não é possível conceber um modelo explicativo causal no processo epistêmico da mesma, uma vez que, em se tratando de processos mentais, tem-se uma condição da qual não se pode extrair causas, mas sim motivos. Entretanto, é possível entrever uma semelhança entre explicação psicanalítica e explicação causal (típica das ciências da natureza) - muito embora ambas jamais se confundam -, pois o que se quer apreender na primeira refere-se ao que está subjacente, mais especificamente enquanto motivo e não enquanto causa, dos conteúdos manifestos conscientemente. Caso se queira determinar um juízo universal referente à causa eficiente de uma dada espécie de patologia mental, tal como analogamente se faz quando de uma explicação científica, a tentativa resultará num comprometimento das conclusões da análise psicanalítica, porque estas serão perigosamente reificadas e estarão alienadas de uma interpretação específica para a peculiaridade de cada caso clínico, a partir da qual se obtêm os motivos e não as causas previsíveis dos distúrbios mentais.

Portanto, as considerações feitas até aqui nos apresentam duas noções distintas acerca do estatuto epistemológico da psicanálise, a saber: de um lado, temos Assoun (1978) concebendo uma démarche homogênea fundamentada na singularidade da psicanálise caracterizada por um tipo de racionalidade investigativa em que a explicação de modo algum se encontra apartada da interpretação; por outro lado, Ricoeur posiciona-se em relação a tal estatuto considerando-o essencialmente calcado num modelo interpretativo, segundo o qual uma explicação do tipo causal implicando leis gerais está fora de cogitação. Se se fizesse apelo a alguma explicação do tipo causal, tratar-seia, em todo caso, de uma causalidade singular. Isto é o que assemelharia a psicanálise à história. 5

Neste contexto, delineamos um quadro de referência baseado nas diferentes posições conceituais entre os autores em questão, através do qual pretendemos discutir à seguinte questão: há uma especificidade da psicanálise dentro do contexto científico? Considerando-se que esta, ainda nos dias atu-

\footnotetext{
${ }^{5}$ Este assunto é mais complexo e veremos como, de certo modo, Ricoeur aceita uma eficácia causal do ponto de vista econômico (que ele chama de "Energética") que está solidamente entrelaçado, e também dependente, em termos heurísticos, do nível hermenêutico.
} 
ais, sofre constantes questionamentos em função de apresentar uma condição de ser peculiar no que se refere ao "caráter científico", uma vez que não está estruturada estritamente de acordo com os princípios e práticas relativos ao rigor metodológico das ciências da natureza, a mesma tende a suscitar diversas polêmicas e controvérsias para as quais pretendemos desenvolver algumas elucidações.

A este respeito, atentemos para o fato de que teóricos das mais diversas áreas do conhecimento, como epistemólogos, lógicos, filósofos da linguagem e semanticistas concluíram que falta à psicanálise, uma fundamentação de fato científica, já que se aperceberam que, ao examinarem os conceitos psicanalíticos, estes implicavam proposições, argumentações e estrutura teórica, cujas articulações não comportam condições necessárias e suficientes para satisfazerem às exigências requeridas por uma teoria científica.

Neste particular, cabe uma importante consideração, a saber: o ponto essencial sobre o qual recai a conclusão acima referida embasa-se no caráter metodológico da psicanálise, que se caracterizaria pela interpretação. Assim, Paul Ricoeur destaca da crítica do empirismo lógico à psicanálise aquela que é feita por Ernest Nagel, que faria a seguinte imputação à psicanálise.

Seu material adere à relação singular do analista com o analisando; não se pode afastar a dúvida de que a interpretação é imposta aos fatos pelo intérprete, por falta de um processo comparativo e de investigação estatística; enfim, as alegações dos psicanalistas concernentes à eficácia terapêutica não satisfazem às regras mais elementares da verificação". (RICOEUR, 1977, p.286-287).

Em contrapartida, ainda que alguns teóricos dirijam seus esforços a uma reformulação da psicanálise, no sentido de uma tentativa de enquadrá-la às normas científicas de uma teoria, aproximando-a, por exemplo, da psicologia, esta solução nos parece inviável, em virtude de que, como aponta Ricoeur:

(...) a diferença será inicial ou jamais existirá: a psicologia é uma ciência de observação, que versa sobre os fatos da conduta; a psicanálise, uma ciência exegética, que versa sobre as relações de sentido entre os objetos substituídos e os objetos originários (e perdidos) da pulsão. É desde o início, no próprio 
nível da noção inicial de fato e de inferência a partir dos fatos, que as duas disciplinas divergem. (RICOEUR, 1977, p.294).

Um outro ponto relevante, neste contexto, e que diferencia a psicanálise da psicologia são as variáveis do ambiente, as quais são abordadas sob perspectivas distintas nestas duas teorias. No trecho abaixo, Ricoeur (1977, p. 297) retrata bem esta questão:

"Elas não são para o analista, de forma alguma fatos, tais
como estes são conhecidos pelo observador exterior. O que
importa para o analista são as dimensões do meio ambiente,
tais como o sujeito "acredita" que sejam; o que é pertinente
para ele não é o fato, mas o sentido que o fato tomou na his-
tória do sujeito".

Desse modo, pode-se dizer que a conduta para o analista expressa alterações de sentido na história do sujeito, não sendo, portanto, como para o psicólogo, uma variável dependente, ou seja, observável de fora.

Em vista disso, Ricoeur (1977, p. 298) diz que "não há 'fatos' em psicanálise, porque não se trata aí de observar, mas de interpretar”. Neste caso, mais uma vez, podemos notar que há visíveis diferenças de objeto entre a psicologia e a psicanálise.

Um outro exemplo encontrado a respeito da afirmação acima, no texto em exame, é o seguinte:

(...) a psicanálise é um trabalho de palavra com o paciente, o que a psicologia científica de alguma forma é. É num campo de palavras que a "história" do paciente vem expressar-se; consequentemente, seu objeto próprio são esses efeitos de sentido - sintomas, delírios, sonhos, ilusões - que a psicologia empírica pode considerar apenas como segmento de conduta. Para o analista é a conduta que é um segmento do sentido. Eis por que objeto perdido, objeto substituído são o pão cotidiano da psicanálise. Para o analista, a ausência não é um segmento numa cadeia de variáveis observadas, mas um fragmento desse mundo simbólico que aflora no interior do campo fechado da palavra que é a análise enquanto talking cure. (RICOEUR, 1977, p.299). 
Neste contexto, Ricoeur (1977, p.298), ao indagar o que é pertinente em psicanálise, diz: "Se não se reconhece a especificidade das questões de sentido e de duplo-sentido, e se não se liga essa questão à do método de interpretação pelo qual essa questão se coloca, a "realidade psíquica" da qual fala a psicanálise será sempre apenas uma causa supérflua”.

É nesse sentido que Monzani, um dos grandes estudiosos da epistemologia da psicanálise freudiana, afirma que ainda que o discurso desta psicanálise seja constituído, por um lado, por um arsenal lingüístico e conceitual do positivismo, é importante lembrarmos que, por outro:

(...) a psicanálise se revela como uma pesquisa do sentido, uma busca constante das significações ocultas, o que se torna claro no diálogo analítico, em que uma profusão de sentidos velados se prolifera de um lado é decifrada do outro. Decifração e interpretação constituem o essencial desse trabalho. (MONZANI, 1991, p.118)

Diante deste quadro, queremos sublinhar que, malgrado a relevância e o fato de ser insubstituível, para a configuração da psicanálise, o plano da interpretação, o pai da psicanálise pensava que tal plano devia ter como fundamento sólidas bases teóricas construídas alhures do dito plano.

A seguir, trataremos de alguns aspectos da dimensão prática psicanalítica, a partir dos conceitos de Energética e de Hermenêutica. Discutiremos $o$ ponto de vista energético, a fim de caracterizarmos um sistema mecânico de forças (plano ontológico do sistema psíquico) que irá tanto estimular o processo hermêutico quanto estar sob sua análise. 


\section{0 ponto de vista energético}

A obra freudiana, de acordo com Paul Ricoeur (1977), é tida como um discurso misto e ambíguo, no sentido de que, por um lado, apresenta conflitos de forças justificando uma energética (na medida em que Freud concebe o funcionamento do sistema psicossomático enquanto um processo mecânico cuja finalidade está em manter constante ou a um nível mais baixo possível a quantidade de energia oriunda de excitações endógenas e externas) e, por outro, relações de sentido justificando uma hermenêutica. Tal ambigüidade parece ser o que caracteriza e fundamenta a psicanálise, já que temos na mesma a peculiar situação epistemológica, segundo a qual a essência energética da psique (na qual se processam aqueles conflitos de forças) é desvelada pelo processo decifrador e interpretativo da hermenêutica; pode-se dizer que "a energética passa por uma hermenêutica e que a hermenêutica descobre a energética. Este ponto é aquele em que a posição do desejo se anuncia num e por um processo de simbolização.” (RICOEUR, 1977, p.67).

No entanto, esta proposição, que o autor pretende justificar na primeira parte de seu livro, De l'interpretation: essai sur Freud, apresenta (como ele próprio explicitou) um difícil e grande conflito com a complexidade constituída pelo problema do sentido ou da representação, no que se refere à explicação do funcionamento energético da mente. Por que complexidade? Segundo Ricoeur, quando Freud propôs um conhecimento da mente que a compreendesse como um sistema mecânico de forças (que fique bem claro: sistema este distinto do sistema nervoso e que guarda com o mesmo uma forte reciprocidade de influências), assim pôde fazer na medida em que prescindiu da consciência intencional da fenomenologia. Ora, tal proceder parece tender a uma explicação naturalista da mente e negligenciar o estudo da constituição simbólica típica desta última. Logo, dado que a hermenêutica lida com significações e não com relações de força, conclui-se que a psicanálise, ao tratar da mente com um vocabulário tópico-econômico que discorre sobre tais relações, não é uma hermenêutica. Este argumento, que constitui a referida complexidade, é justamente aquilo que o autor refuta, afirmando que a representação não é antinômica relativamente às noções de pulsão, de objetivo de pulsão e de afeto, possibilitada pelo fato de se haver estruturado, ao longo do desenvolvimento do pensamento freudiano, uma interpenetração entre explicação tópica-econômica e interpretação de significações (esta últi- 
ma desenvolvida em análises clínicas), interpenetração esta que possibilitaria uma interpretação do sentido pelo sentido.

Todo o problema da epistemologia freudiana parece concentrar-se numa única questão: como é possível que a explicação econômica passe por uma interpretação que versa sobre significações e, em sentido oposto, que a interpretação seja um momento da explicação econômica? (...) Talvez seja na própria posição do desejo que residem ao mesmo tempo a possibilidade de se passar da força à linguagem, mas também a impossibilidade de se retomar a força na linguagem. (RICOEUR, 1977, p.68).

Para percorrermos com clareza as reflexões que este problema reclama, mostra-se importante considerarmos o ponto de vista energético, já que, conforme o exposto acima, são as características lógicas, conceituais que constituem a energética, que suscitam as controvérsias acerca da possibilidade da representação ou significação serem passíveis de ser decifradas pela hermenêutica. Para tanto, sendo a noção freudiana a princípio econômica, aquilo que Ricoeur designa por energética, iremos estudar tal noção.

A fim de abordarmos o conceito de ponto de vista econômico ${ }^{6}$, é preciso ter em vista os fatos clínicos ou os dados empíricos particulares dos quais a análise interpretativa extraiu uma hipótese particular acerca dos processos psíquicos, a saber, a hipótese da defesa, já que foi a partir desta hipótese que Freud pôde inferir um esboço do princípio geral de funcionamento do aparelho psíquico, qual seja, o princípio econômico.

Freud demonstrou ter compreendido de forma apurada a natureza daqueles fatos clínicos (como, por exemplo, a histeria, a neurose obsessiva, etc.), pois sentiu a necessidade de não reduzir suas explicações a processos neurofisiológicos, fatos esses que pressupõem que Freud não era adepto da teoria reducionista da psique; os fenômenos psíquicos patológicos observados e analisados na clínica foram considerados enquanto entidades com relativo grau de independência frente aos processos fisiológicos. Portanto, foi necessária a construção de hipóteses através de um método com certo nível de espe-

${ }^{6}$ É junto com os pontos de vista tópico e dinâmico, o que caracteriza uma abordagem metapsicológica. (Edição Standard Brasileira, v.XIV, cfr. Artigo "O inconsciente". 
culação, para que fosse possível dar conta da explicação de tais fenômenos. A primeira destas hipóteses a ser construída por Freud, a qual refere-se à explicação destes últimos e correspondente ao primeiro passo da constituição de uma teoria geral da psique que fora denominada metapsicologia - a qual tem como um de seus pilares, o ponto de vista econômico -, diz respeito justamente à teoria da defesa.

Para compreendermos melhor este ponto e o ponto de vista energético ou econômico, analisemos uma noção bastante crucial usada por Freud para explicar a dinâmica inerente às forças em luta implicadas nos processos de repressão e resistência, que caracterizam os mecanismos de defesa - ou de resolução de conflitos - de que se vale a mente a fim de dissipar seus distúrbios, qual seja: a noção de "quota de afeto".

A título de uma breve explicação, precisamos fazer uma caracterização do conceito de afeto e, em seguida, explicitar o vínculo deste conceito relativamente ao conceito de "quota de afeto". Segundo Green (1982), o significado do termo afeto remete ao conjunto dos estados subjetivos qualitativos associados às emoções, paixões, sentimentos, sendo que tais estados estão intimamente relacionados aos processos neurofisiológicos. $O$ afeto, para Freud, possui a propriedade de ser dinâmico, na medida em que, quando uma força psíquica atua na repressão de uma certa representação mental no inconsciente, a quantidade de afeto (quota de afeto) associada a esta representação é dissociada da mesma, o que gera o seu deslocamento, transformação e circulação para outras áreas. Vejamos o seguinte trecho:

(...) o afeto quantitativamente determinado ou "quantum de afeto" - seja ele entendido como uma forma de manifestação de uma "soma de excitação", ou seja visto como "o aspecto quantitativo energético ligado ao aspecto qualitativo subjetivo (do afeto)" - quando dissociado do componente representativo, tem a propriedade de ser deslocável, fluente, (...). (MILIDONI, 1993, p.55)

Ainda segundo Milidoni (1993), nos textos de Freud da época imediatamente anteriores à "Comunicação Preliminar" (1893), a abordagem quantitativa referia-se estritamente a processos neurofisiológicos que dividiam espaço com determinados processos psíquicos, mas que já em 1894 a hipótese quantitativa diz respeito estritamente às funções psíquicas. 
No âmbito da clínica, segundo esta autora, a descoberta das resistências é o marco inicial que fundamenta a teoria da defesa e, consequentemente, uma perspectiva dinâmica na abordagem de processos psicológicos. Para Milidoni (1993, p.16) “(...) a introdução desta hipótese [da defesa] se encontra revestida de uma importância fundamental, já que implica de fato em por em marcha o que será "o ponto de vista econômico em Psicanálise".

A perspectiva dinâmica sob a qual está inserida a teoria da defesa, de acordo com Milidoni, está de fato em outro nível, qual seja, "o do conflito entre representações e o ego", e a partir desta postulação, ela formula a seguinte indagação:

O que será esse fator quantitativo, que é paralelizado com uma "quota de afeto" ou "soma de excitação", e que parece ser fundamental para o traçado dos caminhos do afeto no mecanismo defensivo? Em que sentido valeria a equivalência entre "quota de afeto" e "soma de excitação"? (MILIDONI, 1993, p.18)

Tentando elucidar as ponderações expostas acima, vejamos que, em Neuropsicoses de defesa (1894), Freud formula uma hipótese geral acerca da propriedade quantitativa do psíquico, a qual constitui o fundamento do ponto de vista econômico:

(...) nas funções mentais deve ser distinguida alguma coisa uma quota de afeto ou soma de excitação - que apresenta todas as características de uma quantidade (embora não dispomos de meios para medi-la) capaz de crescimento, diminuição, deslocamento, descarga e que se espalha sobre os traços de memória das idéias, tal como uma carga elétrica que se expande na superfície de um corpo. (FREUD, 1894 /1976, p.73)

Logo, conclui Milidoni (1993, p.18) que:

“(...) a hipótese se justifica, mesmo que provisoriamente, pela sua potência explicativa e pela aptidão para estabelecer conexões a nível fenomênico; pois, que estaríamos frente a uma hipótese de nítido teor instrumental, que é capaz de preencher adequadamente suas funções (explicar, coordenar) manipu- 
lando o postulado fator quantitativo "como se" ele fosse, realmente, uma quantidade... Quão longe poderá ir a potência explicativa desta hipótese?”

Voltando às inter-relações entre os conceitos de "soma de excitação" e "quantum de afeto" um ponto que deve ser ressaltado é que, de acordo com Laplanche e Pontalis (1996), embora tais conceitos sejam apresentados enquanto sinônimos, cada uma dessas expressões é na realidade utilizada para designar diferentes aspectos do fator quantitativo. Portanto, quando se toma quantitativamente o afeto enquanto soma de excitação, a semântica designada conduz a um fator de origem do afeto ligado a uma ação causal de estímulos externos e internos sobre a estabilidade da constância funcional do aparelho psíquico, no qual, consequentemente, se acumula uma soma de excitação ou uma quota de afeto. Já ao se usar a expressão quantum de afeto, o sentido que se quer sustentar remete a uma imensurável quantidade referente ao grau de intensidade da manifestação do afeto, a qual perdura sem mudanças de extensão frente às vicissitudes das transformações do mesmo afeto.

Para ampliarmos um pouco mais nossa explicação, faz-se necessário entendermos quais as implicações da fluência das quotas de afeto nos processos do mecanismo de defesa. Para tanto, discutiremos a dissociação entre afeto e representação que ocorre em tais processos, a partir da seguinte postulação:

O que é recalcado e portanto passa a existir no regime do inconsciente é a representação, à qual esse afeto está originalmente ligado. Processado o recalque, o afeto se encontra, por assim dizer, livre e freqüentemente se desestrutura em angústia. Essa angústia tende coercitivamente a se ligar a uma outra representação e passa a ser percebida como expressão dessa última representação. O trabalho analítico em larga medida é a tentativa de descobrir, de colocar a claro esses "descaminhos do afeto" e reconduzi-lo à sua representação original. (MONZANI, 1989, p. 251)

De fato, a distinção entre representação e afeto é um dos eixos centrais que constitui a psicanálise freudiana. Segundo esse ponto de vista: "a grande descoberta da psicanálise foi perceber que não há relação intrínseca entre representação e afeto e que, ao contrário, essa relação é de uma pura 
soldagem entre uma e outra, de sorte que são passíveis de se dissociarem e tomarem rumos distintos”. (MONZANI, 1989)

A crítica de Monzani a Ricoeur, nesse sentido, é referente à essência da descoberta da psicanálise, isto é, à independência do afeto e da representação. Para ele, a psicanálise constitui-se em duas teses básicas, a saber: "todo ato psíquico é formado por dois componentes, que geralmente aparecem ligados entre si - um componente representativo (a idéia, podemos dizer) e um componente afetivo (ou emoção, sentimento)" (MONZANI, 1989, p.91). Este autor atenta para os dois pressupostos de Ricoeur (1977), os quais consistiriam em dizer que: "a energia é inimiga mortal do sentido e o afeto é impensável sem uma representação"; caso contrário, este último não poderia situar-se no âmbito da psicologia, nem da psicanálise, ficando, portanto, reduzido ao domínio do fisiológico. Portanto, para Monzani, nas postulações de Ricoeur não há possibilidade de interação entre energética e hermenêutica na psicanálise freudiana, já que ele visa excluir totalmente o plano econômico do psíquico.

Para Ricoeur, segundo Monzani (1989, p.94): “(...) a grande viragem da Traumdeutung foi no sentido de subordinar a explicação (entenda-se o discurso da Metapsicologia) à interpretação”. Desse modo, a teoria do aparelho psíquico deve provir da teoria do sentido, sendo, portanto, a primeira subordinada à segunda. Devido a este fato, a possibilidade de adequação entre ambas as teorias, torna-se nula, já que é a energética que fundamenta a hermenêutica, muito embora esta última seja a fonte heuristicamente privilegiada para a construção da teoria do aparelho psíquico.

Logo, Monzani atenta, a seu juízo, para esta problemática análise de Ricoeur, dizendo que este último faz uma análise inadequada do conceito de "presentação psíquica" - como conceito expressivo - no qual força e sentido se encontram diante da noção de pulsão:

Para Freud, ao que tudo indica, há um momento preliminar de transformação e a pulsão é exatamente esse "conceito limite" que aponta para o momento mesmo onde os processos energéticos orgânicos transformam-se em processos energéticos psíquicos. (MONZANI, 1989, p.94)

No entanto, entendemos que, para Ricoeur (1977), o contraste que há entre energética e hermenêutica não se resolve por eliminação de uma ou de 
outra destas vertentes epistemológicas. Ele diz que "o freudismo não existe senão pela recusa dessa alternativa”, do contrário, isso implicaria num retalhamento da teoria. A possibilidade de expressão da psicanálise, segundo o autor, reside numa dialética entre força e sentido. Ele refere-se ao Projeto $^{7}$ como o estado energético da teoria, o qual não comportaria uma hermenêutica; a contrapartida ou antítese se dá com o surgimento da hermenêutica no contexto das investigações do texto $A$ interpretação dos sonhos (1900); e, por fim, a síntese, isto é, a interação entre força e sentido seria finalmente encontrada nos escritos metapsicológicos (1915). Nestes escritos, de acordo com Franco (1995), a integração entre energética e hermenêutica amadurece: há uma relação entre o próprio conceito de pulsão, um conceito energético e sua representação, que pede uma interpretação.

Todavia é preciso atentar à seguinte advertência de Monzani (1989, p.103):

“A interpretação, (...) não está tematizada no texto do Proje-
to... Mas há uma enorme diferença entre o fato de uma noção
não estar tematizada e estar ausente. A interpretação está pre-
sente no texto e, em vários pontos, explicitamente. Na verda-
de, esta interligação é constante no texto, conforme se pode
apreender das várias afirmações de Freud que abrem a parte II
do Projeto...” [Parte essa, por sinal, intitulada Psicopatologia]

Em vista de tudo o que fora dito, podemos tomar preliminarmente um parecer significativo perante a estrutura interpretativa da epistemologia freudiana, mediante as considerações acerca do ponto de vista energético, qual seja, a dinâmica que caracteriza os processos energéticos da psique não se mostra absolutamente avessa à penetração da hermenêutica, já que os mesmos devem ser articulados sistematicamente com os conceitos constituintes da metapsicologia, a fim de que possa existir efetivamente uma psicanálise.

${ }_{7}^{7}$ Projeto de uma psicologia, Editora Imago, tradução de Osmyr F. Gabby Jr, 1995. Este texto compunhase originalmente na forma de um manuscrito redigido por Freud em 1895 e no qual tentava-se apresentar um modelo de mente em termos de quantidades e neurônios. 


\section{As hipóteses psicanalíticas e seus níveis: a teoria da defesa}

A importância de analisar a teoria da defesa, no contexto do presente artigo, reside no fato de que o seu desenvolvimento comporta duas dimensões essenciais que toda metodologia científica deve possuir, a saber: a observação de um determinado conjunto de fenômenos empíricos, a princípio enigmáticos, e a explicação dos mesmos.

Para tanto, conduziremos nossa investigação a partir da relação entre a idéia de defesa psíquica e a formação de sintomas, uma vez que foi a partir da análise desta relação que Freud desenvolveu a teoria que investigaremos.

Para iniciarmos nossa análise, faz-se necessário, num primeiro momento, configurar o panorama epistemológico que distingue na psicanálise três níveis constituintes a fim de que possamos situar nestes últimos o papel desempenhado pela teoria da defesa. Vejamos em que consistem tais níveis segundo a classificação freudiana apontada por Laplanche e Pontalis (1995, p.384-385):

“A) Um método de investigação que consiste essencialmente em evidenciar o significado inconsciente das palavras, das ações, das produções imaginárias (sonhos, fantasias, delírios) de um sujeito. Este método baseia-se principalmente nas associações livres do sujeito, que são a garantia da validade da interpretação. A interpretação psicanalítica pode estender-se a produções humanas para as quais não se dispõe de associações livres.

'B) Um método psicoterápico baseado nesta investigação e especificado pela interpretação controlada da resistência, da transferência e do desejo. O emprego da psicanálise como sinônimo de tratamento psicanalítico está ligado a este sentido; exemplo: começar uma psicanálise (ou uma análise).

'C) Um conjunto de teorias psicológicas e psicopatológicas em que são sistematizados os dados introduzidos pelo método psicanalítico de investigação e tratamento". 
Se atentarmos bem para a definição acima, pode-se depreender uma classificação dos níveis das hipóteses psicanalíticas estruturada em duas categorias: de um lado, temos aqueles níveis relativamente próximos da base fenomênica (sintomas), através dos quais se tenta compreender os sintomas à luz de certas hipóteses explicativas (por exemplo, a hipótese da relação causal trauma-sintoma, presente nos primeiros estudos sobre a histeria); de outro, temos os níveis vinculados a um campo explicativo de uma tendência mais abstrata, os quais, ao longo da história psicanalítica, gradualmente tendem à constituição das hipóteses metapsicológicas. Como veremos adiante, a estruturação da teoria da defesa se dá dentro dos limites respeitantes a ambas as categorias referidas acima:

Constata-se, que na sua teoria da defesa, Freud não mais verá os estados hipnóides enquanto "substrato" a partir do qual derivar-se-ia (...) uma divisão da consciência; no novo esquema explicativo, ele irá colocar, na raiz dessa divisão, que é acompanhada da formação de "grupos psíquicos separados", "um ato de vontade" por parte do sujeito, "cujo motivo pode ser especificado". (MILIDONI, 1993, p.15)

É importante ressaltar que a teoria da defesa é o marco inicial do rompimento teórico entre as idéias de Freud e Breuer no que diz respeito ao mecanismo psíquico da histeria:

Breuer dava preferência a uma teoria que era, se poderia dizer, até certo ponto fisiológica; tentava explicar a divisão mental nos pacientes histéricos pela ausência de comunicação entre vários estados mentais ("estados de 'consciência", como chamávamos naquela época), e construiu então a teoria dos "estados hipnóides" cujos produtos se supunham penetrar na "consciência desperta" como corpos estranhos não assimilados. Eu via a questão de forma menos científica; parecia não discernir por toda parte senão tendências e motivos análogos aos da vida cotidiana, e encarava a própria divisão psíquica como o efeito de um processo de repulsão que naquela época denominei de "defesa", e depois de "repressão". (FREUD, 1914 /1996, p.21) 
Em Neuropsicoses de defesa (1894), Freud caracteriza a defesa enquanto um mecanismo psíquico utilizado para reprimir alguma idéia tingida por uma certa coloração afetiva, idéia essa que o sujeito não é capaz de tolerar. Tal mecanismo é acionado quando o ego precisa reprimir, isto é, expulsar da consciência, alguma idéia que lhe cause desprazer.

$\mathrm{O}$ mecanismo gerador da histeria, resumidamente, consiste em uma retenção de afetos produzidos por situações traumáticas, os quais, não encontrando meios normais para serem exteriorizados, agem, por um lado, como fonte de constante excitação do psiquismo e, por outro, são deslocados para as vias somáticas e, consequentemente, manifestados como sintomas físicos, ou seja, resíduos do trauma.

O fator desencadeante da excitação referida acima está circunscrito às operações inconscientes, cujos processos de lembrança de situações traumáticas ocorridas no passado emergem na estrita medida em que há uma determinada experiência atual que lhes suscite a ocorrência. De fato, é isso que nos mostra a citação que se segue: “(...) nenhum sintoma histérico pode emergir de uma experiência real isolada, mas em todos os casos a lembrança de experiências mais antigas, despertadas em associação com ela, atua na causação do sintoma." (FREUD, 1896/1976, p.223)

É importante para o nosso entendimento acerca da gênese da histeria e, consequentemente, da teoria da defesa nos reportarmos, também, à idéia de que esta última encontra-se embasada, num primeiro momento, sobre a resistência, a partir da qual Freud fundamentou sua concepção quanto à histeria:

Nesta idéia de resistência alicercei então minha concepção acerca dos processos psíquicos na histeria. Para o restabelecimento do doente mostrou-se indispensável suprimir estas resistências. Partindo do mecanismo da cura, podia-se formar uma idéia muito precisa da gênese da doença. As mesmas forças que hoje, como resistência, se opõem a que o esquecido volte à consciência deveriam ser as que antes tinham agido, expulsando da consciência os acidentes patogênicos correspondentes. A esse processo, por mim formulado, dei o nome de 'repressão' e julguei-o demonstrado pela presença inegável da resistência. (FREUD, 1909/1970, p. 25)

Diante do exposto, o que nos interessa é saber de que maneira Freud estabeleceu a vinculação causal entre a defesa e a produção de sintomas. Para 
tanto, faz-se necessário, num primeiro momento, entendermos a relação que se estabelece entre a defesa (repressão) e o inconsciente, já que os sintomas, segundo Freud, são resultantes de lembranças que operam inconscientemente. Vejamos o exemplo abaixo:

(...) a repressão não impede que o representante pulsional continue a existir no inconsciente, se organize ainda mais, dê origem a derivados [sintomas], e estabeleça ligações. $\mathrm{Na}$ verdade, a repressão só interfere na relação do representante pulsional com um único sistema psíquico, a saber, o do inconsciente. (FREUD, 1915d/1996, p.153-154)

Podemos agora compreender melhor como a teoria da defesa, ou, da repressão estruturou-se como a 'pedra angular da psicanálise freudiana'. Recorrendo à História do movimento psicanalítico (1914), um texto de Freud, vemos que nele é concebida tal teoria enquanto: “(...) a formulação teórica de um fenômeno que pode ser observado quantas vezes se desejar se se empreende a análise de um neurótico, sem recorrer à hipnose”.

Na medida em que a repressão na histeria só se torna possível pela extensa formação de substitutos, ela pode ser julgada inteiramente destituída de êxito [pelo retorno do reprimido em forma de substitutos]; contudo, ao lidar com a quota de afeto - a verdadeira tarefa da repressão -, ela geralmente significa um êxito total. $\mathrm{Na}$ histeria de conversão, o processo de repressão é completado pela formação do sintoma (...). (FREUD, 1915d/1996, p.160-161)

Em vista do exposto, para finalizarmos nossas considerações sobre a construção da teoria da defesa, será relevante evidenciar o significado epistemológico expresso por esta capital teoria, a fim de que possamos estabelecer, pelo menos em princípio, até que ponto a psicanálise pode ser tomada como ciência.

No que diz respeito à esfera empírica da investigação, tem-se que a construção da teoria da defesa satisfaz as condições impostas pela metodologia científica, na medida em que tal construção implica necessariamente na observação atenta e na descrição detalhada dos dados obtidos a partir da prática clínica, tais como, por exemplo, um sintoma manifestado por uma 
histeria de conversão. É importante lembrar que, para Freud, não há qualquer tipo de observação e descrição que esteja desacompanhada de uma espontânea aplicação de conceitos primitivos ou conceitos fundamentais, como é possível constatar no trecho introdutório a "Pulsões e seus destinos"

Já no que concerne à esfera especulativa da investigação, a construção da mesma teoria manifesta processos de dedução racional que intervêm posteriormente na coleta dos dados acima referidos, no sentido de que promovem ajustes, reconfigurações, ordenamentos e aperfeiçoamentos daqueles conceitos primitivos. Neste sentido, Freud necessitou de recorrer a um plano de reflexão especulativa para reformular as conclusões das pesquisas de Breuer (vinculadas ao âmbito da fisiologia) a respeito da histeria, consistindo tal reformulação no fato de que Freud "percebeu" a existência de um mecanismo de resistência à cura por parte dos pacientes ${ }^{9}$, o que teria sido impossível no contexto dos estados hipnóides e do método hipnótico.

\section{Energética e Hermenêutica: 0 conceito de pulsão}

A temática que propomos desenvolver neste tópico do artigo se refere a uma abordagem da teoria das pulsões, a fim de compreendermos de que forma um conceito metapsicológico pode se estruturar de acordo com a realidade empírica, expressando por um lado, um viés energético e por outro uma hermenêutica.

Segundo James Strachey, editor inglês, responsável pelas notas introdutórias do artigo de Freud, As pulsões e seus destinos (1915), o termo pulsão aparece na obra freudiana somente a partir dos Três ensaios (1905). Antes disso, expressões como 'excitações', 'idéias afetivas', 'estímulos endógenos', apareciam, provavelmente, como precursores do termo em questão. Aliás, vale ressaltar que o conceito de pulsão é um dos pilares da metapsicologia.

Strachey relata que Freud por diversas vezes se mostrou insatisfeito diante do conhecimento que obtivera sobre as pulsões, em função da carência de material teórico sobre o qual pudesse se apoiar. Entretanto, como diz este editor, Freud considerava as pulsões como 'o elemento ao mesmo tempo

\footnotetext{
${ }^{8}$ Cf. tópico: A metapsicologia.

${ }^{9} \mathrm{Na}$ verdade, Freud percebeu um rechaço dos pacientes à terapia quando esta os conduzia perto das lembranças patogênicas. O nome "resistência" e a própria idéia de resistência já implicava na aplicação de um conceito teórico postulado por Freud.
} 
mais importante e mais obscuro da pesquisa psicológica', como foi dito em Além do princípio de prazer (1920).

Freud, nas Novas conferências introdutórias sobre psicanálise, diz que a teoria das pulsões é a mitologia da psicanálise. Esta referência aparece na carta de Freud a Einstein (1933): "Talvez você tenha a impressão de que nossas teorias constituem uma espécie de mitologia... Mas toda ciência da natureza não propõe tal espécie de mitologia? Acontece diferentemente com você, na física de hoje?”.

Diante do exposto, para iniciarmos nossa abordagem, faz-se necessário, num primeiro momento, discorrer sobre a origem e a natureza do conceito de pulsão na teoria freudiana, ao qual, por vezes, atribui-se uma definição confusa, em conseqüência das dificuldades trazidas pelo problema de tradução do termo Trieb, originário da língua alemã e que se refere ao termo que designamos como pulsão.

O embrião do conceito de pulsão está profundamente vinculado à noção do princípio de constância formulada por Freud por meio de suas investigações acerca do funcionamento do aparelho psíquico. Segundo tal princípio, a estrutura psico-somática recebe determinadas excitações causadoras de estados de tensão, os quais, por sua vez, se resultam em quantidades de energia em excesso, devem ser eliminadas da referida estrutura, fato este que implica na necessidade de mecanismos reguladores de uma constância energética, a qual consiste em manter a totalidade das excitações num nível quantitativo o mais baixo possível ou, pelo menos em mantê-lo constante. (FREUD, 1996 [1920], p.18)

É a partir deste princípio, portanto, que podemos verificar a elaboração do conceito em questão: os fatores fundamentais responsáveis pela descarga de tais estados excessivos de tensão são as pulsões, cuja natureza reside em ser processos dinâmicos oriundos do organismo e constitutivos de uma pressão que exerce uma força constante, e cujo conceito situa-se na fronteira entre o somático e o psíquico. A pulsão apenas pode ser percebida mediante representações e afetos, afetos esses por cuja descarga o organismo é impelido a realizar a meta de descarregar a energia que nele está em excesso. Assim, de acordo com Monzani (1989, p.250), pode-se dizer que: "A pulsão enquanto tal é e nos será sempre desconhecida. O que nos aparece no plano psíquico é um seu representante, um seu delegado, o qual é possível (sob certas condições) ser conhecido". 
Segundo Ricoeur (1977, p.110) é a partir da problemática do objetivo e do objeto [da pulsão] que podemos pensar em "destinos de pulsão"; sendo o estudo das fontes (Quelle) da excitação da competência da biologia; só conhecemos a pulsão em seus objetivos e seus objetos: somente eles dependem da psicologia. Isto é, o aparelho que consideramos é um aparelho psíquico e a regulação pelo prazer-desprazer é de ordem psicológica, embora envolva elementos quantitativos. É importante ressaltar que para Freud (1920/1996, p.19) “o princípio de prazer" decorre do princípio de constância; na realidade, esse último princípio foi inferido dos fatos que nos forçaram a adotar o princípio de prazer.” Desta forma, Freud afirma que:

(...) é incorreto falar na dominância do princípio de prazer sobre o curso dos processos mentais. Se tal dominância existisse, a imensa maioria de nossos processos mentais teria de ser acompanhada pelo prazer ou conduzir a ele, ao passo que a experiência geral contradiz completamente uma conclusão desse tipo. O máximo que se pode dizer, portanto, é que existe na mente uma forte tendência no sentido do princípio de prazer, embora essa tendência seja contrariada por certas outras forças ou circunstâncias, de maneira que o resultado final talvez nem sempre se mostre em harmonia com a tendência no sentido do prazer. (FREUD, 1920/1996, p.19)

É possível observar desde já que o termo "pulsão" e não “instinto" aproxima-se de maneira mais eficaz ao sentido que Freud quis dar do termo Trieb, pois que a ênfase que se quer dar aos processos de descarga energética acima referidos (aos quais Freud atribui este último), não corresponde aos procedimentos de um comportamento estabelecido hereditariamente, mas sim a uma força inconsciente suscitada por estímulos endógenos ao organismo, dos quais ela é expressão, o que implica em atividades do sistema nervoso mais complexas do que as requeridas pelo instinto.

É importante assinalar, também, a função essencial do conceito de pulsão para a descrição e explicação dos processos psíquicos sob as relações dinâmicas, tópicas e econômicas, isto é, para a explicação do aparelho psíquico segundo uma metapsicologia.

O funcionamento psíquico guarda suas raízes no jogo entre o consciente-pré-consciente e o inconsciente, que está longe de ser estático, já que os conflitos e as composições de forças de origem pulsional geradoras das pres- 
sões no organismo originam tal funcionamento, e aqui temos o aspecto dinâmico da psique. Já o aspecto econômico desta última confere-lhe a explicação segundo a qual a natureza dos processos psicológicos reside na circulação e repartição de uma energia pulsional quantificável. E, por último, tem-se que a influência exercida pelas pulsões proporciona justamente a funcionalidade dos três sistemas de que se compõe o aparelho psíquico, a saber, o Inconsciente, o Pré-consciente e o Consciente (Primeira tópica) ou, o Id, o Ego e Superego (Teoria estrutural), cada qual destes designando, de certo modo, três distintos lugares psíquicos, donde emerge uma concepção tópica da psique (o termo "tópica" denotando uma teoria dos lugares):

Poderíamos dizer que a tópica é esse lugar não anatômico, psíquico, que deve ser introduzido na teoria psicanalítica como a condição de possibilidade de todos os "destinos de pulsões", e o mercado dos investimentos onde se trocam pulsões do ego e pulsões de objeto. (RICOEUR, 1977, p.116)

Resumidamente, podemos dizer, tendo por base Laplanche e Pontalis (1995), que no que se refere à primeira tópica, o Inconsciente (Ics) constituise por conteúdos originários do processo de recalque (conteúdos estes, que representam as pulsões) para os quais o acesso ao sistema pré-conscienteconsciente foi negado em conseqüência daquele último.

Segundo Monzani (1989), na primeira tópica, tem-se a idéia de um 'sistema inconsciente' no qual o 'inconsciente' era confundido com o recalcado e, desse modo, a instância recalcadora estabelecia-se no sistema préconsciente. No entanto, a partir dessa idéia surgem varias questões acerca da problemática do conteúdo do conflito e dos limites do que não é consciente em relação ao "sistema inconsciente". Nesse sentido, "a experiência analítica mostra que, quando se trata de fazer emergir as resistências, aquilo que recalca, o sistema defensivo, está no mesmo nível inconsciente que a instância recalcada” (p.237). Por outro lado, é preciso ter em conta que aquilo que é inconsciente não deve ser identificado com o "sistema inconsciente"; por exemplo, os conteúdos do Id; que são qualitativamente inconscientes.

É importante ressaltar, ainda de acordo com o autor acima citado, que além destas contradições encontradas na Primeira Tópica, outras de cunho conceitual foram percebidas por Freud especialmente no que diz respeito ao "problema da composição do inconsciente e a reformulação da 
noção de ego". Tais fatos levaram Freud a repensar o conceito de defesa e, consequentemente, o funcionamento do aparelho psíquico de acordo com a primeira tópica. E é no contexto da Segunda Tópica, na Conferência XXXI das Novas Conferências Introdutórias sobre a Psicanálise (1932), que a emergência das pulsões no aparelho psíquico, se faz patente pela sua irrupção no Id, sempre via seus representantes ideativos e afetivos.

Assim, podemos dizer, de acordo com Monzani (1989, p.185), que:

(...) a pulsão aparece no domínio do psíquico como uma energia que pressiona no sentido da descarga através de um objeto apropriado (que pode ser o próprio corpo do sujeito, eventualmente). É por isso que, no inconsciente, essa energia aparece em estado livre, não ligado, pressionando freneticamente no sentido de sua finalidade. Se o inconsciente se caracteriza por um estado livre e selvagem da energia, com uma quase total mobilidade, é porque está inscrito na natureza da pulsão.

Ricoeur crê que, no tocante à psicanálise, não há conflito entre as duas ordens de linguagem, acima mencionadas, isto é, entre energética e hermenêutica. E aponta o conceito de pulsão em Freud como o lugar desta harmonia. Desse modo, o reconhecimento da pulsão enquanto conceito fundamental da teoria psicanalítica freudiana marca a passagem do campo descritivo para o campo sistemático, isto é:

“(...) é finalmente na relação entre pulsão, como primeiro conceito energético, e a apresentação da pulsão, como conceito hermenêutico, que reside a especificidade do discurso analítico, o qual une os dois universos da força e do sentido numa semântica do desejo". (RICOEUR, 1977, p.216)

O caráter ambíguo que caracteriza a psicanálise parece ser "solucionado”, para alguns teóricos, no Projeto... (1895), já que, neste trabalho, Freud expressa sua teoria à luz de uma energética. Segundo Ricoeur (1977) é neste contexto que ocorre o "divórcio inicial entre explicação e interpretação". Em A interpretação dos sonhos (principalmente no capítulo VII), a teoria parece integrar pela primeira vez, energética e hermenêutica; e, finalmente, nos arti- 
gos Metapsicológicos (1914-1917), tal integração se afirma: há uma relação entre o próprio conceito de pulsão, um conceito energético e sua representação, que pede uma interpretação. (FRANCO, 1995, p.110).

É importante considerarmos que a opinião de Monzani (1989, p.114), nesse sentido, difere da leitura, acima, postulada por Ricoeur, vejamos o seguinte trecho:

\begin{abstract}
"Não se trata de divórcio, mas de níveis diferentes que Freud sempre faz questão de manter. O trabalho da interpretação chega a certas teses que são colocadas no nível da linguagem do sentido, mas que, segundo ele, Freud, devem ser colocadas e encaixadas na linguagem teórica que formula os problemas em termos de processos psíquicos. É essa a linguagem da $\mathrm{Me}$ tapsicologia (...); é ela que deve dar conta dos efeitos de sentido; existiria, assim, uma subordinação recíproca entre interpretação e explicação, cada uma a seu nível: a interpretação produz teses que a explicação fundamenta”.
\end{abstract}

Enfim, averiguamos, com a imprescindível e essencial ajuda de uma breve análise acerca da teoria das pulsões, a maneira pela qual os conceitos fundamentais (os Grundbegriffe) da Metapsicologia, de um modo geral, se estruturam a partir de uma prática científica, a fim de ampliarem-lhe e dirigirem-lhe, respectivamente, a extensão e o processo explicativos, mediante o esclarecimento dos mecanismos mentais (especialmente o inconsciente), que exercem profunda influência na vida do sujeito.

\title{
A Metapsicologia
}

O fator que nos levou a desenvolver o presente tópico advém das próprias condições epistemológicas que determinam os procedimentos investigativos da psicanálise. A natureza do objeto de estudo por esta visado, na medida em que se constitui de profundas "cavidades" não presentes no plano da consciência (isto é, dos processos inconscientes), necessita de duas solidárias linhas de investigação ao mesmo tempo. Com efeito, como pode ser visto junto a Assoun (1978), tem-se que uma das linhas é a empírica, calcada, basicamente, na esfera da percepção dos fatos singulares (notadamente os sintomas). A outra linha retrata justamente o tópico desta seção: dada à insuficiência das explicações empíricas, a psicanálise se vê forçada a adotar um 
método especulativo que não deve se confundir com um apriorismo filosófico, mas, sim, compor-se segundo um aparelho conceitual arraigado profundamente na referência constante à experiência: trata-se, portanto, neste caso, da metapsicologia; isto é, um arcabouço teórico que estrutura a psicanálise freudiana e é também, uma "perspectiva” de investigação psicanalítica.

Um dos motivos que levaram Freud a criar o termo metapsicologia foi o de referir-se a uma doutrina da psique humana que se diferencia essencialmente das tradicionais ciências psicológicas fundamentadas tão-somente na percepção sensório-motora do organismo. Isto porque a estrutura do inconsciente, que constitui o capital objeto de estudo da psicanálise, não pode ser detectada e compreendida meramente através de estudos anatômicos e neurofisiológicos, pelos quais apenas pode-se compor um panorama explicativo da mente caracterizado pelas explicações dos mecanismos perceptuais e cognitivos da consciência físico-química.

No entanto, podemos dizer que, ao mesmo tempo em que Freud não restringiu a elaboração de sua nova teoria psíquica ao âmbito das explicações neurofisiológicas, também não tencionava estruturá-la sobre um aparato conceitual metafísico, e, portanto, pretendia elaborar um conhecimento endopsíquico do funcionamento mental do qual resulta uma realidade não perceptível pela consciência imediata, cuja fundamentação explicativa é a de uma psicologia do inconsciente.

É de se notar que a elaboração do conhecimento acima referido (a metapsicologia) se dá mediante um processo explicativo que se reporta à abordagem dos fatos psíquicos considerados, através de uma dependência que devem possuir em relação às aplicações de idéias abstratas não determinadas pela experiência e, portanto, desprovidas, a princípio, de qualquer conteúdo empírico. Em outras palavras, tais idéias constituem um dos eixos fundamentais que regem a investigação psicanalítica, sem o qual a observação dos fenômenos mentais permaneceria um ato predominantemente mecânico e alheio a uma percepção científica.

Assoun (1978), ao falar sobre a Gênese da metapsicologia e seu sentido, cita um trecho de uma correspondência de Freud a Fliess (a carta de 12 de dezembro de 1896), na qual ele refere-se à metapsicologia como: "Meu filho ideal, meu filho problema: a metapsicologia”. O autor em questão faz uma interpretação interessante a este respeito: 
Esses termos traduzem um verdadeiro investimento afetivo de Freud em sua própria disciplina, que materializa algo de essencial. Filho, porque já considera essa disciplina como aquilo que lhe é o mais intimamente ligado, como o rebento que ele abriga amorosamente. Mas filho fictício, problemático e ideal; filho virtual de quem não se sabe se vai dar à luz, nem mesmo o que ele é; filho sobre o qual pesa a suspeita de monstruosidade, mas que também contém a promessa capital de realização da psicanálise como um além que condiciona a realização de sua verdadeira identidade. (ASSOUN, 1978, p.68-69)

A complexidade teórica envolvida a respeito do conceito de metapsicologia acarreta uma certa dificuldade de explicação e de justificação epistemológica acerca do mesmo. Tal fato levou Freud (1937/1996, p.241) a comparar a metapsicologia com uma Feiticeira. Isto é: a bruxa metapsicologia. "Sem especulação e teorização metapsicológica - quase disse 'fantasiar'-, não daremos outro passo à frente”. Esta parece ter sido a maneira que Freud encontrou para justificar uma teoria que tende a ir além de uma representação empírica.

$\mathrm{Na}$ teoria psicanalítica freudiana, o emprego do termo "metapsicológicas" designa um conjunto de idéias abstratas (por exemplo: as de aparelho psíquico, libido, pulsão) passíveis de alterações, somente, na medida em que apresentarem correlações significativas com o material empírico, e cuja função na investigação é compor uma "superestrutura especulativa em psicanálise”. Nesse sentido, Freud (1925/1974, p.305) diz que, “a psicanálise está firmemente alicerçada na observação dos fatos da vida mental e por essa mesma razão sua superestrutura teórica ainda está incompleta e sujeita a constante alteração".

Em Pulsões e seus destinos (1915), Freud oferece um paradigma epistemológico para a investigação da função e da natureza da metapsicologia:

Ouvimos com freqüência a afirmação de que as ciências devem ser estruturadas em conceitos básicos claros e bem definidos. De fato, nenhuma ciência, nem mesmo a mais exata, começa com tais definições. O verdadeiro início da atividade científica consiste antes na descrição dos fenômenos, passando então a seu agrupamento, sua classificação e sua correlação. Mesmo na fase de descrição não é possível evitar que se 
apliquem certas idéias abstratas ao material manipulado, idéias provenientes daqui e dali, mas por certo não apenas das novas observações. Tais idéias - que depois se tornarão os conceitos básicos da ciência - são ainda mais indispensáveis à medida que o material se torna mais elaborado. Devem de início, possuir necessariamente certo grau de indefinição; não pode haver dúvida quanto à qualquer delimitação nítida de seu conteúdo. Enquanto permanecem nessa condição, chegamos a uma compreensão acerca de seu significado por meio de repetidas referências ao material de observação do qual parecem ter provindo, mas ao qual, de fato, foram impostas. (FREUD, 1915c/1996, p.123)

Desse modo, para compreendermos o processo que culminou nos conceitos fundamentais metapsicológicos, temos que ter sob análise aqueles pressupostos epistemológicos explicitados por Freud, segundo os quais um processo investigativo científico diz respeito, inicialmente, à observação e descrição dos fatos empíricos e quase que concomitantemente, ao surgimento das idéias primitivas da futura fundamentação de uma ciência psicanalítica aplicadas ao material empírico daqueles fatos.

Uma caracterização mais apurada da metapsicologia como uma perspectiva metodológica, só viria a se constituir, por volta de 1915, quando Freud a apresenta através de seus artigos metapsicológicos. Vejamos o trecho abaixo, retirado do artigo Um estudo autobiográfico:

(...) fiz uma tentativa para produzir uma 'Metapsicologia'. Com isso eu queria dizer um método de abordagem de acordo com o qual todo processo mental é considerado em relação com três coordenadas, as quais eu descrevi como dinâmica, topográfica e econômica, respectivamente; e isso me pareceu representar a maior meta que a psicologia poderia alcançar. (FREUD, 1925/1974, p.74)

Diante do exposto, pode se perceber que o eixo da construção da metapsicologia está em instaurar um complexo corpo de conceitos essenciais que possa nitidamente servir de sólido alicerce para o desenvolvimento e a condução de uma prática científica que perfaça uma verdadeira ciência psicanalítica. A legítima racionalidade psicanalítica, neste contexto, a fim de se 
identificar com a formação de conceitos diretrizes que estejam rigorosamente inscritos nas determinações empíricas, edifica-se na estrita medida da intervenção da abstração racional no processo descritivo dos fenômenos, isto é, os conceitos fundamentais psicanalíticos se constituem paulatinamente conforme a construção objetiva do objeto, possibilitada pela avaliação do material empírico aos mesmos conceitos:

Já ouvi dizer várias vezes em tom de desprezo que é impossível aceitar seriamente uma ciência cujos conceitos mais gerais se ressentem de exatidão, como os da libido e da pulsão na psicanálise. Mas essa censura repousa numa concepção totalmente errônea dos fatos. Conceitos básicos claros e definições vivamente traçadas somente são possíveis nas ciências mentais até o ponto em que estas procuram ajustar uma região de fatos no arcabouço de um sistema lógico. Nas ciências naturais, das quais a psicologia é uma delas, tais conceitos gerais nítidos são supérfluos e na realidade impossíveis. (FREUD, 1925/1974, p.73)

Vale ressaltar que os conceitos fundamentais da psicanálise originamse de um tipo singular de abstração que lhe confere sua própria especificidade, na medida em que seu procedimento epistêmico racional exige, para sua validade positiva e objetiva, a recorrência constante à experiência.

Em resumo, são estes conceitos de base proveniente desta espécie peculiar de abstração racional que, ao mesmo tempo, fornecem um suplemento psicológico (a metapsicologia) aperfeiçoador da démarche empírica e proporcionam o advento da psicanálise, de forma que viabiliza à mesma a constituição de seu estatuto epistemológico.

No presente trabalho percorremos um campo amplo em busca de uma integração teórica geral das perspectivas da psicanálise freudiana, na tentativa de considerar a hipótese de que a interpretação é um dos elementos fundamentais que caracterizam a epistemologia desta psicanálise, já que, ao ser empregada no trabalho clínico tendo em vista fins terapêuticos, simultaneamente tem a finalidade de ser empregada na construção teórica de um modelo explicativo do psiquismo humano. 
Vimos que o emprego da técnica hermenêutica confere à epistemologia freudiana um procedimento metodológico e explicativo cuja racionalidade não se enquadra rigorosamente nos padrões convencionais da pesquisa das ciências empíricas. Tais padrões caracterizam-se, de certa forma, por fundamentarem a pesquisa em um sistema axiomático constituído por postulados matemáticos (e seu correspondente grupo de operações) e em métodos experimentais racionalmente construídos. A psicanálise freudiana, ao se deparar com as dificuldades epistêmicas, postas pela propriedade subjetiva, de seu objeto de pesquisa, se viu impelida a criar técnicas hermenêuticas para elucidar os motivos subjacentes à dimensão semântica ambígua constituinte do funcionamento mental humano, servindo-se para tanto, de uma perspectiva energética em que são expressas relações de forças através das quais se processa a estrutura semântica do mental.

A dinâmica que se processa nas relações de forças pulsionais, representadas conceitualmente pela metapsicologia, só pôde ser descrita em suas leis gerais na medida em que Freud se baseou numa racionalidade experimental atuante na esfera da clínica terapêutica. A teoria do funcionamento psíquico humano, em Freud, surgiu, também, em decorrência de preocupações médico-terapêuticas. Isso significa que a ele não bastavam as análises propriamente objetivas da neurofisiologia para lidar eficientemente com os diversos distúrbios psíquicos. Era preciso pressupor condições experimentais novas que possibilitassem uma melhor compreensão teórica dos fenômenos mentais; que articulassem racionalmente, na clínica terapêutica, diversos fatos isolados com base já em certas hipóteses, a fim de encontrar na concatenação deles, determinados padrões de funcionamento mental.

Mas que tipo de fatos? Aí é que entra a questão hermenêutica no freudismo. As propriedades subjetivas da mente não podem cair sob as representações das fórmulas matemáticas, pois os processos causais na esfera do subjetivo, segundo o freudismo, caracterizam-se pela determinação do comportamento intencional da mente pelo funcionamento do campo de forças que atuam na mesma mente. Esta determinação só é apreensível conceitualmente em condições experimentais específicas, como as proporcionadas pela prática clínica psicanalítica, na qual o discurso lingüístico e outros tipos de referentes (por exemplo, um ato falho) expressos na livre-associação oriunda do paciente devem ocupar o cerne da psicanálise, o que implica em transpassar a aparência da semântica imediatamente manifestada por tais referentes a 
fim de apreender-lhes a semântica latente, que constitui os motivos da disfunção psíquica ao nível das relações de forças.

Ora, esta análise do sentido feita pelo viés energético pressupõe uma técnica hermenêutica que permita lidar com relações de duplo sentido, e não propriamente com relações de grandezas que se exprimem por fórmulas lógico-matemáticas. Logo, acreditamos que a racionalidade específica da epistemologia freudiana pode ser caracterizada através da hermenêutica e da energética, e que o significado da interpretação na episteme psicanalítica está no fato de ela contribuir para explicar racionalmente a estrutura funcional da subjetividade humana*.

\footnotetext{
* Agradeço ao Professor Dr. Richard Theisen Simanke (Departamento de Filosofia e Metodologia das Ciências da UFSCar) pela revisão deste artigo.
} 


\section{Referências Bibliográficas}

ASSOUN, P.L. Introdução à Epistemologia Freudiana. Rio de Janeiro: Imago. 1983. . Freud: a filosofia e os filósofos. Rio de Janeiro: Francisco Alves. 1978.

BARBELLI, I.C. $A$ interpretação na psicanálise freudiana: uma abordagem epistemológica. Dissertação (Mestrado em Filosofia) - Faculdade de Filosofia e Ciências, Universidade Estadual Paulista. Unesp - Marília. 2005.

FRANCO, S.G. Hermenêutica e Psicanálise na obra de Paul Ricoeur. Coleção Filosofia; 35. São Paulo: Loyola. 1995.

FREUD, S. Projeto de uma psicologia. Tradução: O.F. Gabbi Júnior. Rio de Janeiro: Imago. 1895/1995.

As neuropsicoses de defesa. In: Edição Standard Brasileira das Obras Psicológicas Completas de Sigmund Freud. Rio de Janeiro: Imago. 1894/1976.

A etiologia da histeria. In: Edição Standard Brasileira das Obras Psicológicas Completas de Sigmund Freud. Rio de Janeiro: Imago. 1896/1976.

A interpretação dos sonhos. In: Edição Standard Brasileira das Obras Psicológicas Completas de Sigmund Freud. Rio de Janeiro: Imago. 1900/1996.

A história do movimento psicanalítico. In Edição Standard Brasileira das Obras Psicológicas Completas de Sigmund Freud. Rio de Janeiro: Imago. 1914/1996.

Artigos sobre metapsicologia. In Edição Standard Brasileira das Obras Psicológicas Completas de Sigmund Freud. Rio de Janeiro: Imago. 1915a/1996.

O inconsciente. In: Edição Standard Brasileira das Obras Psicológicas Completas de Sigmund Freud. Rio de Janeiro: Imago. 1915b/1996.

Os instintos e suas vicissitudes (Pulsões e seus destinos) In: Edição Standard Brasileira das Obras Psicológicas Completas de Sigmund Freud. Rio de Janeiro: Imago. 1915c/1996.

. Repressão. In: Edição Standard Brasileira das Obras Psicológicas Completas de Sigmund Freud. Rio de Janeiro: Imago. 1915d/1996.

Além do princípio do prazer. In: Edição Standard Brasileira das Obras Psicológicas Completas de Sigmund Freud. Rio de Janeiro: Imago. 1920/1996.

Novas conferências introdutórias sobre a psicanálise. In: Edição Standard Brasileira das Obras Psicológicas Completas de Sigmund Freud. Rio de Janeiro: Imago. 1932/1996.

. Cinco lições de psicanálise. In: Edição Standard Brasileira das Obras Psicológicas Completas de Sigmund Freud. Rio de Janeiro: Imago. 1909/1970. 
. Um estudo autobiográfico. In: Edição Standard Brasileira das Obras Psicológicas Completas de Sigmund Freud. Rio de Janeiro: Imago. 1925/1974.

. Construções em análise. In: Edição Standard Brasileira das Obras Psicológicas Completas de Sigmund Freud. Rio de Janeiro: Imago. 1937/1996.

GREEN, A. O discurso vivo: uma conceituação psicanalítica do afeto. Rio de Janeiro: F. Alves. 1982.

LAPLANCHE, J. Vocabulário da Psicanálise: Laplanche e Pontalis. São Paulo: Martins Fontes. 1996

MASSON, J. M. A correspondência completa de Freud para Wilhelm Fliess. Rio de Janeiro: Imago. 1986.

MILIDONI, C.B. Heurística freudiana no "Projeto para uma psicologia científica". Tese de Doutorado em Filosofia apresentada no IFCH da UNICAMP. 1993.

MONZANI, L.R. Freud: o movimento de um pensamento. Campinas: Editora da Unicamp. 1989.

. Discurso filosófico e discurso psicanalítico: balanço e perspectivas. (Org.) JUNIOR, Bento Prado. In: Filosofia da Psicanálise. São Paulo: brasiliense, 1991.

RICOEUR, P. Da interpretação: ensaio sobre Freud. Rio de Janeiro: Imago. 1977.

STRENGER, C. Between hermeneutics and science. An essay on the epistemology of psychoanalysis. Madson, Connecticut: International Universities Press, 1994.

TAYLOR, C. Force et sens: les deux dimensions irréductibles de une science de homme. In: Sens et Existence: em hommage a Paul Ricoeur. (Org. Gary Brent Madison) Paris: Éditions du Seuil. 1975.

E-mail: belbarbelli@yahoo.com.b

Recebido: 03/2008

Aprovado: $11 / 08$ 